\title{
TMO-App: construção e validação de aplicativo para familias de crianças/adolescentes com câncer
}

BMT-App: development and validation of a mobile application for families of children/adolescents with cancer TMO-APP: elaboración y validación de aplicación para familias de niños/adolescentes con cáncer

\author{
Adriana Maria Duarte ${ }^{1}$ i https://orcid.org/0000-0002-2762-5030 \\ Myriam Aparecida Mandetta² ${ }^{2}$ inttps://orcid.org/0000-0003-4399-2479
}

Duarte AM, Mandetta MA. TMO-App: construção e validação de aplicativo para famílias de crianças/ adolescentes com câncer. Acta Paul Enferm. 2022;35:eAPE03502.

DOI

http://dx.doi.org/10.37689/acta-ape/2022A003502

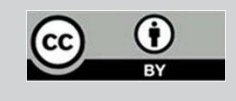

Descritores

Família; Transplante de células-tronco hematopoiéticas: Aplicativos móveis; Neoplasias

Keywords

Family; Hematopoietic stem cell transplantation; Moblle applications; Neoplasms

Descriptores

Familia; Trasplante de células madre hematopoyéticas: Aplicaciones móviles; Neoplasias

Submetido 24 de Novembro de 2020

Aceito

31 de Maio de 2021

Autor correspondente

Adriana Maria Duarte E-mail: adrianaduarte@unb.br

Editor Associado (Avaliação pelos pares): Alexandre Pazetto Balsanel (https://orcid.org/0000-0003-3757-1061) Escola Paulista de Enfermagem, Universidade Federal de São Paulo, São Paulo, SP, Brasil

\section{Resumo}

Objetivo: Construir e validar uma tecnologia informativa para famílias de crianças/adolescentes com câncer submetidos ao transplante de células-tronco hematopoiéticas.

Métodos: Estudo metodológico fundamentado no Modelo do Cuidado Centrado no Paciente e Família e UserCentered Design, realizado em quatro etapas: avaliação das necessidades de informações; construção teórica e desenvolvimento do aplicativo; validação de conteúdo e semântica pelo comitê de juízes e populaçãoalvo; avaliação da usabilidade por experts em informática. Os participantes do estudo foram profissionais e famílias de crianças com câncer. Para a validação de conteúdo e semântica, estabeleceu-se percentual de concordância entre juízes de 80\% e Índice de Validade de Conteúdo de 0,8. Para a avaliação da usabilidade foram utilizadas as heurísticas de Nielsen. Os dados foram analisados por meio de estatística descritiva.

Resultados: Após identificação das necessidades de informações da família, na literatura e no estudo de campo, e construção do aplicativo, este foi validado por especialistas, obtendo percentual de concordância de $87 \%$ e índice de validade de conteúdo de 0,87; e pela população-alvo, de $98 \%$ e 0,98, respectivamente. Quanto a usabilidade, atingiu o grau de severidade simples. 0 aplicativo móvel TM0-App apresenta 268 telas e 95 ilustrações, contemplando as necessidades de informações da família antes, durante e após o transplante.

Conclusão: Os métodos utilizados para o desenvolvimento e validação mostraram-se satisfatórios para atingir os objetivos propostos. 0 aplicativo construído é confiável, de fácil uso, útil, completo e adequado. 0 estudo avança na proposição de nova estratégia informativa para promover o empoderamento da família em situação de doença crônica.

\section{Abstract}

Objective: To develop and validate an informative technology for families of children/adolescents with cancer undergoing hematopoietic stem cell transplantation.

Methods: A methodological study grounded on the Patient-and Family-Centered Care Model and UserCentered Design, conducted in four stages: assessment of information needs; theoretical construction and development of the mobile application; content and semantic validation by a committee of experts and target population; usability evaluation by computer experts. The participants of the study were professionals and families of children with cancer. For content and semantic validation, an inter-rater agreement percentage of $80 \%$ and a Content Validity Index of 0.8 were established. For usability evaluation, Nielsen's heuristics were used. The data were analyzed using descriptive statistics.

Results: After the information about the family's needs was obtained from the published literature and field study, the application was developed and validated by experts. Agreement of $87 \%$, and a content validity index 
of 0.87 , were achieved with the expert group; $98 \%$ and 0.98 , respectively, with the target population. With regard to usability, the level of simple severity was reached. The BMT-App mobile application contains 268 screens and 95 illustrations, addressing the family's information needs before, during, and after transplantation.

Conclusion: The methods used for development and validation were satisfactory to achieve the intended objectives. The application constructed is reliable, easy to use, useful, complete, and adequate. The study advances the proposition of a new informative strategy to promote empowerment of the family confronting chronic disease.

\section{Resumen}

Objetivo: Elaborar y validar una tecnología informativa para familias de niños/adolescentes con cáncer sometidos al trasplante de células madre hematopoyéticas.

Métodos: Estudio metodológico fundamentado en el Modelo del Cuidado Centrado en el Paciente y la Familia y User-Centered Design, realizado en cuatro etapas: evaluación de las necesidades de información, construcción teórica y desarrollo de la aplicación, validación semántica y del contenido por el comité de jueces y el público destinatario, evaluación de usabilidad por especialistas en informática. Los participantes del estudio fueron profesionales y familias de niños con cáncer. Para la validación semántica y de contenido, se estableció un porcentaje de concordancia entre los jueces del 80 \% y un Índice de Validez de Contenido de 0,8. Para la evaluación de usabilidad se utilizaron las heurísticas de Nielsen. Los datos fueron analizados mediante estadística descriptiva.

Resultados: Después de identificar las necesidades de información de la familia, en la literatura y en el estudio de campo, y de elaborar la aplicación, esta fue validada por especialistas y obtuvo un porcentaje de concordancia del 87 \% y un Índice de Validez de Contenido de 0,87. A su vez, los resultados del público destinatario fueron 98 \% y 0,98, respectivamente. Respecto a la usabilidad, alcanzó un nivel de severidad simple. La aplicación móvil TM0-App presenta 268 pantallas y 95 ilustraciones que contemplan las necesidades de información de la familia antes, durante y después del trasplante.

Conclusión: Los métodos utilizados para el desarrollo y validación demostraron ser satisfactorios para alcanzar los objetivos propuestos. La aplicación elaborada es confiable, de fácil uso, útil, completa y adecuada. El estudio avanza en la propuesta de una nueva estrategia informativa para promover el empoderamiento de familias en situación de enfermedad crónica.

\section{Introdução}

Com o avanço tecnológico e a evolução nas pesquisas clínicas desenvolvidas na área da Oncologia Pediátrica, o prognóstico de crianças e adolescentes com câncer tem melhorado significativamente. ${ }^{(1)}$ Dentre os avanços disponibilizados, destaca-se o transplante de células-tronco hematopoiéticas (TCTH) ou transplante de medula óssea (TMO) como modalidade terapêutica de alta complexidade, associado a alta morbimortalidade, mas que permite o tratamento de doenças, que antes eram invariavelmente fatais. ${ }^{(2)}$

Apesar de apresentar-se como uma opção de tratamento para prolongar a vida, o TCTH é considerado extremamente desgastante para a família, devido aos longos períodos de espera e hospitalização, separação de membros da família, e até a iminência da morte, como ameaça onipresente. ${ }^{(3,4)}$

Diante de todas as mudanças impostas pela nova situação e as diversas estratégias de enfrentamento descritas na literatura, o processo informativo, legalmente reconhecido, ${ }^{(5)}$ é considerado fundamental para que as famílias compreendam o que está acontecendo com a saúde de seus membros e percebam-se sujeitos ativos no processo saúdel doença, interagindo com a equipe, expondo suas dúvidas, angústias e sentimentos durante todo o tratamento. ${ }^{(3,4)}$

Estudos envolvendo o uso de softwares aplicativos para intermediar a oferta de informaçóes aos pacientes têm apresentado resultados positivos, como a melhora da autoeficácia e do autocuidado; da comunicação sobre a doença entre profissionais, pacientes e famílias; e do suporte para o enfrentamento da situação imposta. ${ }^{(6-9)}$ Estes achados confirmam as atuais tendências para o uso de tecnologias em saúde como estratégias para o cuidado de indivíduos com doença crônica, incluindo o câncer infantojuvenil. ${ }^{(6,10-14)}$

Cientes dos benefícios que este tipo de intervenção pode promover, o desenvolvimento de um aplicativo para famílias de crianças/adolescentes com câncer submetidos a TCTH, abordando questóes sobre o tratamento e manejo da situação, é uma importante ferramenta para o acesso a informação. $\mathrm{Na}$ literatura científica nacional e internacional, não há estudos de ferramentas tecnológicas que traduzam as informações sobre o TCTH para a família, tornando-se imprescindível inovar nesse campo.

Assim, o objetivo deste estudo foi construir e validar uma tecnologia informativa para as famílias de crianças/adolescentes submetidos ao transplante de células-tronco hematopoiéticas. 


\section{Métodos}

Trata-se de estudo metodológico. O referencial teórico do Cuidado Centrado no Paciente e Família $(\mathrm{CCPF})^{(15)}$ e o metodológico User-Centered Design $(\mathrm{UCD})^{(16)}$ fundamentaram o estudo, que foi realizado em quatro etapas: 1 . Avaliação das necessidades de informações da população-alvo na literatura e em pesquisa de campo; 2 . Concepção e construção teórica do aplicativo; 3. Validação de conteúdo e semântica pelo comitê de juízes e população-alvo; e 4. Teste de usabilidade por experts em informática.

$\mathrm{Na}$ primeira etapa, foram realizados dois estudos: revisão integrativa da literatura e estudo de campo, com objetivos idênticos, a fim de se complementarem. Para a revisão, a pergunta norteadora foi: "Quais as necessidades de informaçôes da família da criança/adolescente com câncer durante o tratamento?” A pergunta norteadora ampliada permitiu resgatar estudos referentes ao tratamento do câncer infantojuvenil e analisar os achados com foco na experiência da família no TCTH. As bases de dados consultadas foram PUBMED, MEDLINE, SCIELO e LILACS, utilizando os descritores, em inglês e português: informação; familiar ou cuidador; e neoplasias. Critérios de inclusão: estudos em periódicos nacionais e internacionais (português, inglês e espanhol), com resumos disponíveis, no período de 2011-2017. Critérios de exclusão: estudos com o foco no tratamento do câncer em adultos e em aspectos genéticos/moleculares. A apresentação e discussão dos resultados foi descritiva.

O estudo de campo foi do tipo exploratório, descritivo e qualitativo, com o objetivo de apreender as necessidades de informações das famílias. $\mathrm{O}$ local para a coleta de dados foi um hospital referência no tratamento do câncer infantojuvenil de Sáo Paulo. A populaçáo-alvo foi famílias de crianças/ adolescentes com câncer que vivenciaram a experiência de ter um filho(a) submetido ao TCTH há pelo menos 30 dias, recrutadas por conveniência. Critérios de exclusão: famílias com barreiras de comunicação; e com crianças/adolescentes em desfecho desfavorável ou situação crítica após o TCTH. Adotou-se a definição "família é quem seus membros dizem que sáo". ${ }^{(17)}$ A coleta dos dados foi realizada pela técnica do Grupo Focal, ${ }^{(18)}$ sendo solicitado às famílias que narrassem sua experiência no manejo da criança em TCTH, explorando suas necessidades de informação. As discussóes foram gravadas em mídia digital e transcritas. A Análise Qualitativa de Conteúdo guiou o processo analítico dos dados. ${ }^{(19)}$

$\mathrm{Na}$ segunda etapa, foi realizado um estudo bibliográfico para fundamentar a construção teórica do aplicativo (textos e ilustraçóes), a partir da análise da etapa anterior, seguindo as orientaçóes propostas por Moreira et al., ${ }^{(20)}$ referentes a elaboração de materiais informativos. Foram utilizados artigos publicados em periódicos indexados, entre 2011 e 2017, livros textos e materiais didáticos, manuais e sites de instituições hospitalares. Para esta etapa, formou-se uma equipe composta por Webdesigner, programador, ilustradora e as pesquisadoras do estudo. Após o levantamento bibliográfico, textos e ilustraçóes foram submetidos a edição e a diagramação, através da estratégia de desenho de interface Wireframe. As imagens selecionadas foram enviadas à ilustradora para o processo de criação. As telas finalizadas foram enviadas ao programador, que definiu a modelagem de dados, a infraestrutura, os tipos de requisição e o tráfego de informaçóes para a construção do protótipo, surgindo a versão I do aplicativo.

$\mathrm{Na}$ terceira etapa, foram realizadas as validações de conteúdo e semântica pelos experts da temática e pela população-alvo, utilizando-se a técnica Delphi. ${ }^{(21)}$ Para compor a amostra de juízes, foi realizada busca na Plataforma Lattes, para identificar juízes que preenchiam no mínimo dois critérios: título de especialista, mestre, doutor ou livre docente; experiência profissional mínima de três anos na área; conhecimento sobre CCPF; experiência em TCTH, na construção/validação de instrumentos, no cuidado à criança/adolescente com câncer. Os juízes avaliaram as informaçóes, considerando: perspectiva dos leitores; clareza do conteúdo; conveniência e facilidade de compreensão dos itens; conceitos abordados com vocabulário claro e objetivo. Em relação as ilustraçóes, avaliaram a adequação da composição visual, sua atratividade e organização, e a quantidade. Após o envio do material, via e-mail, para cada tela do aplicativo, solicitava-se ao avaliador responder - 
manter, alterar ou excluir. A análise dos dados deu-se a partir do Índice de Concordância - IC ( $\geq 80 \%)$ e o Índice de Validade de Conteúdo - IVC $(\geq 0,8)^{(22)}$ entre os juízes. As telas que obtiveram os índices estabelecidos eram mantidas; aquelas que não, eram revisadas e resubmetidas para nova validação, até o consenso final. A apresentação dos resultados foi realizada de forma descritiva. Após esta fase, surgiu a versão II do aplicativo.

A validação semântica pela população-alvo foi realizada em sessão de Grupo Focal. ${ }^{(18)}$ Mantendo os mesmos critérios de inclusão e exclusão do estudo de campo da primeira etapa, diferentes famílias foram recrutadas. Assim, as famílias eram expostas às telas e as pesquisadoras questionavam sobre os seguintes aspectos: aparência geral; pertinência dos itens; clareza da linguagem; compreensão dos termos utilizados; representatividade das ilustraçôes; e concordância entre imagens e textos. Para cada tela projetada do aplicativo, as famílias respondiam manter, alterar ou excluir. As telas que obtiveram IC $\geq 80 \%$ e IVC $\geq 0,8$ foram validadas, seguindo a mesma dinâmica de validação pelos juízes. Foi realizada a análise descritiva dos resultados. Após esta fase, surgiu a versão III do aplicativo.

Para o teste de usabilidade, na quarta etapa, utilizou-se as dez heurísticas de Nielsen. ${ }^{(23)}$ Para compor a amostra de juízes, os critérios foram possuir: especialização, mestrado ou doutorado; experiência como Webdesigner por mais de cinco anos; e conhecimento em avaliação pelas heurísticas. Os juízes receberam, por e-mail, os documentos e o link do aplicativo via TestFlight. Para cada heurística, a severidade do problema foi classificada entre 0 a 4 , em que $0=$ sem importância; 1 = cosmético; 2 = simples; 3 = grave; $\mathrm{e}$ $4=$ catastrófico. No caso de classificação 3 ou 4, deveriam ser corrigidas; e entre 0 e 2 , a avaliação poderia ser finalizada. Os dados foram apresentados de forma descritiva. Após esta etapa, surgiu a versão final do aplicativo. A avaliação da aplicabilidade pela população-alvo será realizada em estudo posterior.

Todos os aspectos éticos foram respeitados com aprovação pelo Comitê de Ética em Pesquisa ${ }^{(24)}$ (Parecer 1.253.127) (CAAE: 47408015.0.0000.5505). Este estudo foi registrado na Biblioteca Nacional - Ministério da Cultura, sob o número do 788752.

\section{Resultados}

\section{Etapa 1 - Avaliação das necessidades de informações da população alvo}

Na revisão integrativa, foram identificados 16 artigos. Da análise de conteúdo, originaram-se seis categorias referentes às necessidades de informação das famílias: Aspectos gerais do câncer e da terapêutica; Efeitos colaterais e tardios; Plano de cuidados; Estratégias de enfrentamento; Mudanças no estilo de vida antes, durante e após o TCTH; e, Cuidados paliativos.

As necessidades de informaçóes foram sobre a doença, o tratamento (TCTH), resultados esperados, potenciais complicaçóes, efeitos colaterais do tratamento inicial e efeitos tardios. Informaçóes sobre os cuidados diários durante o tratamento no ambiente hospitalar e domiciliar, tanto psicológicos, como físicos foram considerados fundamentais para a participação no cuidado. No ambiente hospitalar, destacam-se as necessidades de ser informada sobre as mudanças no plano de cuidados e de conhecer a equipe de saúde referência. No ambiente domiciliar, os cuidados gerais em casa com a criança/adolescente e os serviços de emergência disponíveis. As famílias querem aprender como lidar com o impacto psicológico do tratamento; com as próprias emoçóes; com situações de estresse e à incerteza imposta pelo tratamento; com restriçôes impostas; como falar sobre a doença/tratamento; e a mudança de papéis e responsabilidades de cada membro. No pós-tratamento, as necessidades são sobre mudanças no estilo de vida, retomada da vida social, cuidados a longo prazo, possibilidade de recidivas e informaçóes relacionadas a cuidados paliativos e à morte.

No estudo de campo, participaram cinco famílias, representadas por 13 familiares (quatro mães, dois pais, um irmão, uma esposa e cinco pacientes). Dentre os tipos de transplantes realizado houve dois autólogos, dois alogênicos aparentados e um alogênico não-aparentado, com tempo pós-transplante variando de seis meses a 15 anos. As idades dos pacientes variaram de 3 a 18 anos. Após a análise, as necessidades das famílias foram agrupadas em três categorias: Informaçôes em fontes seguras; Conhecimento sobre o TCTH; e Acolhimento pela equipe.

No discurso, fica explicitado que a família quer informaçôes em fontes seguras, que possa confiar, 
e que traga conhecimento, prioritariamente com a equipe médica e com a enfermeira. Outras fontes de informaçóes referidas são a internet e de pais de crianças/adolescentes que já vivenciaram o transplante. $\mathrm{O}$ conhecimento requerido quanto ao TCTH refere-se ao conceito e suas fases; ao prognóstico; às complicaçôes; aos direitos; à rede de suporte; como cuidar da criança/adolescente no hospital e em casa; como falar sobre o tratamento com a família nuclear e ampliada; como lidar com os conflitos no ambiente familiar; as complicaçóes tardias do tratamento; os sinais de alerta após o TCTH; e as estratégias para lidar com a criança/adolescente após alta. No entanto, ressalta que quer ser acolhida para que se sinta segura para cuidar da criança/adolescente, sugerindo que as informaçóes abarquem os riscos, mas também os benefícios do tratamento.

A análise das necessidades de informação das famílias de ambas as fontes, revisão integrativa e pesquisa de campo, evidenciou elementos similares, representando a perspectiva do que a família considera relevante conter em um material informativo sobre o TCTH. No estudo de campo, as famílias ampliaram essa perspectiva para a necessidade de informaçóes que respeitem seu tempo para compreender o que está sendo vivenciado.

\section{Etapa 2 - Concepção e construção teórica do aplicativo}

Após a identificação das necessidades de informaçôes das famílias, agregadas da literatura revisada e da pesquisa de campo, a construção do conteúdo teórico baseou-se em um estudo bibliográfico, objetivando respostas a estas necessidades. A organização do conteúdo do aplicativo foi dividida em cinco categorias: Definições; Pré-TMO; TMO; Pós-TMO; e Sinais de alerta (Quadro 1).

Os dados foram encaminhados ao Webdesigner e ao programador, sendo desenvolvidos 38 wireframes para visualização da interface e organização dos ícones e sítios de navegação. Estabeleceu-se uma identidade visual, com a definição de traços dos personagens e paleta de cores, originando um grupo de personagens (Figura 1), representativos ao longo de toda a trajetória do TCTH, sem impactar a concepção dos diferentes grupos culturais e étnicos.
Quadro 1. Distribuição das categorias e da estrutura de conteúdo do aplicativo

\begin{tabular}{|c|c|}
\hline Categoria & Conteúdo \\
\hline 1. Definições & $\begin{array}{l}\text { Conceitos relacionados ao TCTH: medula óssea; células sanguíneas; } \\
\text { transplante de medula óssea (TMO); tipos de transplante; fontes de células- } \\
\text { tronco } \\
\text { Indicações do TCTH } \\
\text { Equipe Multidisciplinar }\end{array}$ \\
\hline 2. Pré-TMO & $\begin{array}{l}\text { Orientações para a tomada de decisão em fazer ou não fazer o TCTH } \\
\text { Mobilização e coleta de células-tronco } \\
\text { Manejo das complicações decorrentes da fase de condicionamento } \\
\text { (quimioterapia e/ou radioterapia) } \\
\text { Primeira consulta ambulatorial } \\
\text { Exames laboratoriais e de imagem pré-internação (paciente e doador) } \\
\text { Avaliação multiprofissional antes do TCTH } \\
\text { Processo de admissão no hospital } \\
\text { Cuidados com o ambiente de internação } \\
\text { Internação } \\
\text { Fases do TCTH } \\
\text { Preparo da criança/adolescente para o TCTH } \\
\text { Rotinas de cuidados diários } \\
\text { Doador }\end{array}$ \\
\hline 3. TMO & $\begin{array}{l}\text { Infusão das células-tronco } \\
\text { Período de espera da "pega" da medula }\end{array}$ \\
\hline 4. Pós-TMO & $\begin{array}{l}\text { Pega da medula } \\
\text { Principais complicações após a pega da medula } \\
\text { Acompanhamento após o TCTH } \\
\text { Cuidados quando o paciente e família retornarem para casa }\end{array}$ \\
\hline $\begin{array}{l}\text { 5. Sinais de } \\
\text { alerta }\end{array}$ & $\begin{array}{l}\text { Principais sinais e sintomas a que a criança/adolescente e sua família } \\
\text { devem estar atentos após a alta hospitalar }\end{array}$ \\
\hline
\end{tabular}

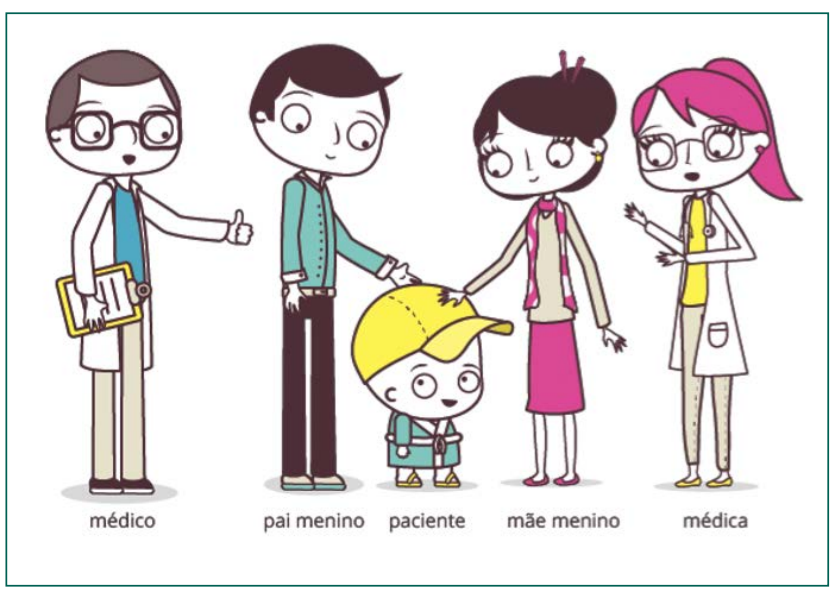

Figura 1. Personagens do aplicativo TMO-App

Neste processo, foi elaborada a imagem representativa do aplicativo e definido seu nome, TMOApp, totalizando 266 telas e 93 ilustraçóes. Ao iniciar o aplicativo, após a tela de termos de uso, surge a interface de apresentação do aplicativo. As categorias foram distribuídas em abas, representadas pelo menu inferior, e as subcategorias representadas por ícones (Figura 2).

O desenvolvimento do aplicativo foi feito para o sistema operacional $I O S$ em dispositivos do tipo tablet Ipad. 


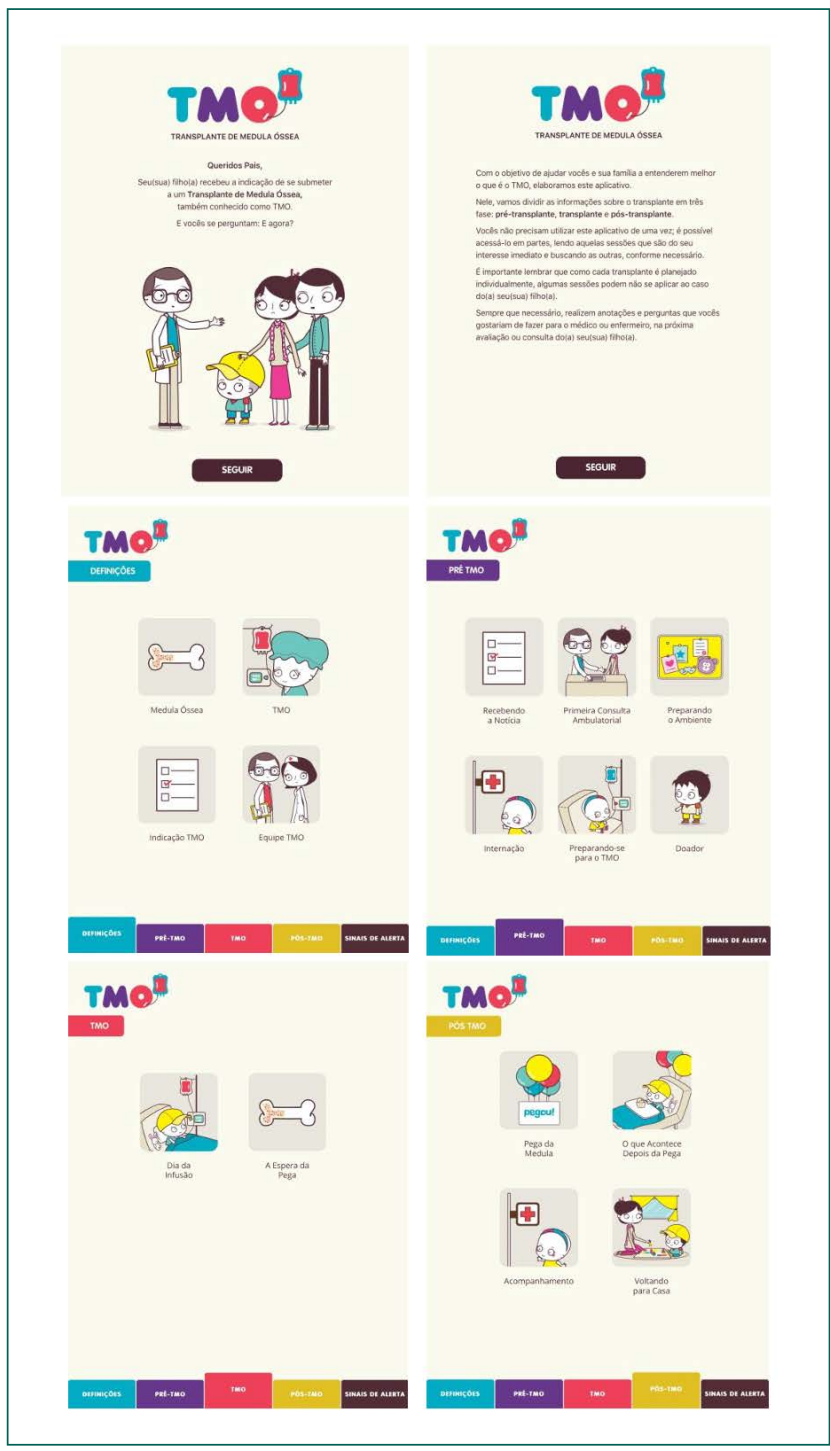

Figura 2. Tela de apresentação, categorias e subcategorias do aplicativo TMO-App

\section{Etapa 3 - Validação de conteúdo e semântica pelo comitê de juízes e população-alvo}

$\mathrm{Na}$ validação pelos juízes, participaram quatro profissionais de saúde (um médico, um enfermeiro assistencial, dois enfermeiros docentes) e um pedagogo, com idade entre 27 e 54 anos. O tempo médio de formação foi de 16,4 anos, com média de 14,4 anos de exercício profissional, sendo três doutores, um mestre e um especialista.

$\mathrm{Na}$ primeira rodada, das 266 telas analisadas, 73 obtiveram concordância de $100 \%(\mathrm{IVC}=1,0)$; 110 de $80 \%$ (IVC=0,8); 57 de 60\% (IVC=0,6); 19 de $40 \%$ (IVC=0,4); e 7 de $20 \%$ (IVC=0,2), totalizando $183(68,8 \%)$ telas com concordância acima de $80 \%$ (IVC $\geq 0,8)$ e $83(31,2 \%)$ abaixo de $80 \%$ (IVC<0,8). Das 83 telas com índices abaixo dos estabelecidos, em $46(55,4 \%)$ a não concordância devia-se a erros de digitação/ortografia, que foram corrigidos. Assim, apenas 37 (44,6\%) foram reenviadas para a segunda rodada de análise. Dessas, obteve-se IC de $100 \%$ em 5 telas (IVC=1,0) e $80 \%$ $(\mathrm{IVC}=0,8)$ em 32 telas. O IVC Global do aplicativo foi de 0,87 e o IC de $87 \%$. Não houve alteraçóes no número de telas e ilustraçóes.

Para a validação com a população-alvo, foram realizadas duas sessôes de grupo focal, com duração de duas horas cada. Participaram cinco mães de cinco famílias, com idade acima de 40 anos, a maioria católica, com ensino médio e superior e média de 2,6 filhos. Apesar da participação somente de mães, solicitávamos que pensassem na experiência da família como um todo.

Dentre os tipos de transplante, houve dois autólogos, dois alogênicos aparentado e um alogênico não-aparentado, com tempo pós-transplante de seis meses a dois anos.

$\mathrm{Na}$ primeira sessão, foram avaliadas 138 telas. Destas, 98,6\% (136) apresentaram concordância acima de $80 \%$ (IVC>0,8); e apenas 1,4\% (2) abaixo do estabelecido (discrepâncias entre conteúdo e ilustraçóes). Na segunda sessão, foram avaliadas 128 telas e reavaliadas as duas telas da primeira rodada, com novas ilustraçóes. Todas as telas obtiveram IC acima de $80 \%$ (IVC>0,8). Na análise geral, as famílias consideraram a linguagem fácil e compreensível; as informações claras e objetivas, com sequência lógica; as ilustraçôes, expressivas e suficientes; as cores, fontes e estruturas gráficas, atrativas; o layout e o design, adequados. O IVC global do aplicativo foi de 0,98 , com 268 telas e 95 ilustrações.

\section{Etapa 4 - Teste de usabilidade por experts em informática}

Participaram três profissionais experts em construção de tecnologias interativas, com média de 24 anos de exercício profissional, sendo dois do sexo feminino e um do sexo masculino; dois doutores e um especialista. A média de idade foi de 52,6 anos.

A avaliação aconteceu off-line, via aplicativo TestFlight. A média de tempo de uso foi de uma 
hora e meia, com identificação de 11 problemas nas heurísticas: nenhum catastrófico; três graves; seis simples; e dois, cosmética. Em uma única rodada, os problemas graves se referiam à programação do aplicativo (único sistema operacional) e, também, um único tipo de dispositivos móvel, sendo acatadas as sugestóes para pesquisas futuras. Algumas correçóes sugeridas como simples e cosméticas, foram incorporadas para ampliar o nível de qualidade, sendo: retirada de nomes comerciais e do botão "VOLTAR" da categoria Sinais de Alerta. Assim, originou-se a versão final do aplicativo.

\section{Discussão}

O estudo metodológico proposto, aliado aos referenciais utilizados, permitiu a construção de um material confiável, preciso e utilizável. A aproximação do CCPF e do UCD foi essencial, pois compartilham a ideia de inclusão do usuário, valorizando suas percepçóes, sentimentos e ações. Ouvir a voz da família, desde a concepção, o planejamento e a validação foram essenciais para que o produto final correspondesse às suas necessidades de informação. ${ }^{(14-16)}$

$\mathrm{O}$ aplicativo $T M O-A p p$ é uma estratégia para promover espaço dialógico com a família, indo ao encontro do que a literatura se refere como tecnologia relacional, em que se valoriza o vínculo e o acolhimento nos espaços de cuidado. Nesse sentido, tem-se por base a visão de mundo, em que a família e a criança são sujeitos de direitos, em uma relação simétrica com a equipe multiprofissional. ${ }^{(25)}$ Embasadas pela informação, as famílias se percebem mais seguras no cuidado de seus filhos, possibilitando fazer melhores escolhas e compartilhar suas percepçóes e conhecimentos. ${ }^{(26)}$ Dessa maneira, o desenvolvimento desse aplicativo torna-se uma ferramenta para ser usada no processo interativo com a família.

O IVC Global do aplicativo e o IC entre os participantes foram considerados excelentes, tendo atingido todos os índices pré-estabelecidos, de acordo com a literatura nacional e internacional. No teste de usabilidade com as heurísticas de Nielsen, as sugestóes contribuíram para o incremento do aplicativo para a versão final.

Estudos internacionais que realizaram a construção de materiais informativos para crianças/ adolescentes com câncer, bem elaborados e de fácil compreensão, evidenciaram que a participação dos usuários nesta construção favoreceu o intercâmbio eficaz de informaçóes e a relação equipe/criança/ adolescente/família; além de melhorar o seu conhecimento. $^{(27,28)}$ No entanto, essas tecnologias ainda são pouco aplicadas na prática com famílias, sendo uma lacuna a ser explorada.

Dado o conhecimento limitado existente na literatura de enfermagem sobre a construção de tecnologias interativas para famílias de crianças/adolescentes com câncer, este estudo avança, pois destaca uma tecnologia interativa, que se apresenta como um novo caminho para promover o empoderamento da família de crianças/adolescentes.

As limitaçóes deste estudo se referem ao sistema operacional que o aplicativo foi desenvolvido - IOS; e ao meio móvel escolhido para disponibilizar as informaçóes - tablet, sendo uma barreira para o acesso de usuários que não os possuem. Novos estudos, em diferentes sistemas e dispositivos, estão sendo desenvolvidos pelas pesquisadoras para ampliar o acesso de futuros usuários.

\section{Conclusão}

A tecnologia construída é válida, uma vez que atingiu os objetivos propostos, demonstrando que é de fácil manuseio, útil, inovadora, completa e com informações importantes. $\mathrm{O}$ processo de construção e validação do aplicativo TMO-App teve como protagonista a família, considerada expert em sua experiência de doença, contribuindo para que o mesmo fosse adequado a sua perspectiva. Com este estudo, evidencia-se que o aplicativo TMO-App pode ser utilizado pela família de crianças/adolescentes com câncer submetidos ao TCTH e, também, pela equipe multiprofissional, em todas as fases da terapêutica. Portanto, é uma estratégia informativa que atende as famílias em seu direito a informação, facilitando seu processo de enfrentamento de maneira fortalecida. 


\section{Colaborações}

Duarte AM e Mandetta MA declaram que contribuíram com a concepção do estudo, análise e interpretação dos dados, revisão crítica relevante do conteúdo intelectual e aprovação final da versão a ser publicada.

\section{Referências}

1. Instituto Nacional de Câncer José Alencar Gomes da Silva (INCA). Estimativa 2020: incidência de câncer no Brasil. Rio de Janeiro: INCA; 2019. $120 \mathrm{p}$.

2. Marques AD, Szczepanik AP, Machado CA, Santos PN, Guimarães PR, Kalinke LP. Hematopoietic stem cell transplantation and quality of life during the first year of treatment. Rev Lat Am Enfermagem. 2018;26(0):e3065.

3. Fairfax A, Brehaut J, Colman I, Sikora L, Kazakova A, Chakraborty P, et al.; Canadian Inherited Metabolic Diseases Research Network. A systematic review of the association between coping strategies and quality of life among caregivers of children with chronic illness and/or disability. BMC Pediatr. 2019;19(1):215-30.

4. Morrison CF, Pai AL, Martsolf D. Facilitators and barriers to selfmanagement for adolescents and young adults following a hematopoietic stem cell transplant [Formula: see text]. J Pediatr Oncol Nurs. 2018;35(1):36-42.

5. Brasil. Conselho Nacional de Defesa dos Direitos da Criança e Adolescente. Resolução $n^{\circ} 41,13$ de outubro de 1995. Dispõe sobre os direitos da criança hospitalizada. Diário Oficial da República Federativa do Brasil 199517 out; Seção l:163. [citado 2021 Mai 26]. Disponível em: http://www.mprs.mp.br/infancia/legislacao/id2178.htm\%3E.\%20 Acesso

6. Mehdizadeh H, Asadi F, Mehrvar A, Nazemi E, Emani H. Smartphone apps to help children and adolescents with cancer and their families: a scoping review. Acta Oncol. 2019;58(7):1003-14.

7. Ana F, Loreto M, José LM, Pablo SM, Pilar MJ, Myriam SA. Mobile applications in oncology: a systemic review of health science databases. Int J Med Inform. 2020;133(104001):1-9.

8. Moody L, Turner A, Osmond J, Hooker L, Kosmala-Anderson J, Batehup L. Web-based self-management for young cancer survivors: consideration of user requirements and barriers to implementation. J Cancer Surviv. 2015;9(2):188-200.

9. Kaltenbaugh DJ, Klem ML, Hu L, Turi E, Haines AJ, Hagerty Lingler J. Using Web-based interventions to support caregivers of patients with cancer: a systematic review. Oncol Nurs Forum. 2015;42(2):156-64.

10. Slater PJ, Fielden PE, Bradford NK. The Oncology family app: providing information and support for families caring for their child with cancer. J Pediatr Oncol Nurs. 2018;35(2):94-102.

11. Fernandes AF, Silva SS, Tacla MT, Ferrari AP, Gabani FL. Information for parents: na allowance for coping with childhood cancer. Semin Cienc Biol Saude. 2018;39(2):145-52.
12. Silva-Rodrigues FM, Moraes KSR, Duarte AM, Polita NB, Padula MPC, Nascimento LC. [Information to parents during childhood cancer treatment: a descriptive study]. Cultura de los Cuidados (Edición digital). 2019;23(54):297-309. Spanish.

13. Davis DW, Logsdon MC, Vogt K, Rushton J, Myers J, Lauf A, et al. Parent education is changing: a review of smartphone apps. MCN in Advance. 2017; 1-10.

14. Barbosa TA, Reis KM, Lomba GO, Alves GV, Braga PP. Support network and social support for children with special health care need. Rev Rene. 2016;17(1):60-6.

15. Institute for Family-Centered Care. Partnering with patients and families to design a patient-and family-centered health care system: recommendations and promising practices. Bethesda, MD; 2008. [cited 2020 Nov 10]. Available from: https://www.ipfcc.org/resources/ PartneringwithPatientsandFamilies.pdf

16. Runaas L, Hanauer D, Maher M, Bischoff E, Fauer A, Hoang T, et al. BMT Roadmap: A user-centered design health information technology tool to promote patient-centered care in pediatric hematopoietic cell transplantation. Biol Blood Marrow Transplant. 2017;23(5):813-9.

17. Wright LM, Leahey M. Enfermeiras e famílias: um guia para avaliação e intervenção na família. 5a ed. São Paulo: Roca; 2012. 327p.

18. Soares MI, Camelo SHH, Resck ZM. Technique of focus group in qualitative data collection: experience report. REME Rev Min Enferm. 2016;20:e942.

19. Vaismoradi M, Jones J, Turunen H, Snelgrove S. Theme development in qualitative content analysis and thematic analysis. J Nurs Educ Pract. 2016;6(5):100-10.

20. Moreira MF, da Nóbrega MM, da Silva Ml. Written communication: contribution to the development of educational material in health. Rev Bras Enferm. 2003;56(2):184-8.

21. Marques JB, Freitas D. The DELPHI method: characterization and potentialities for educational research. Pro-Posições. 2018;29(2):389_ 415.

22. Souza AC, Alexandre NM, Guirardello EB. Psychometric properties in instruments evaluation of reliability and validity. Epidemiol Serv Saude. 2017;26(3):649-59.

23. Nielsen J, Mack RL. Usability inspection methods computer. New Jersey:John Wiley \& Sons; 1994.

24. Brasil. Ministério da Saúde. Conselho Nacional de Saúde. Resolução n 466, de 12 de dezembro de 2012. Disponível em: https://bvsms. saude.gov.br/bvs/saudelegis/cns/2013/res0466_12_12_2012.html

25. Coyne I, Amory A, Gibson F, Kiernan G. Information-sharing between healthcare professionals, parents and children with cancer: more than a matter of information exchange. Eur $\mathrm{J}$ Cancer Care (Engl). 2016;25(1):141-56.

26. Ringnér A, Karlsson S, Hällgren Graneheim U. A person-centred intervention for providing information to parents of children with cancer. Experiences and effects. Eur J Oncol Nurs. 2015;19(3):318-24.

27. Morrison CF, Szulczewski L, Strahlendorf LF, Lane JB, Mullins LL, Pai AL. Designing Technology to Address Parent Uncertainty in Childhood Cancer. ANS Adv Nurs Sci. 2016 ;39(1):15-25.

28. Ikeda AL, Cruz FB, Rosa LM, Anders JC, Radünz V, Fermo VC. Vídeo educativo na fase pré-transplante de células-tronco hematopoiéticas. Rev Enferm UFSM. 2016;6(4):507-17. 